\title{
Response: Commentary: Anthropogenic disturbances jeopardize biodiversity conservation within tropical rainforest reserves
}

\author{
Miguel Martínez-Ramos ${ }^{1 *}$, Iván A. Ortiz-Rodríguez ${ }^{1}$, Daniel Piñero ${ }^{2}$, Rodolfo Dirzo ${ }^{3}$ and \\ José Sarukhán ${ }^{4,5}$ \\ ${ }^{1}$ Laboratorio de Ecología y Manejo de Bosques Tropicales, Instituto de Investigaciones en Ecosistemas y Sustentabilidad, \\ Universidad Nacional Autónoma de México, Morelia, Mexico, ${ }^{2}$ Departamento de Ecología Evolutiva, Instituto de Ecología, \\ Universidad Nacional Autónoma de México, Ciudad de México, Mexico, ${ }^{3}$ Department of Biology, Stanford University, \\ Stanford, CA, USA, ${ }^{4}$ Departamento de Ecología de la Biodiversidad, Instituto de Ecología, Universidad Nacional Autónoma \\ de México, Ciudad de México, Mexico, ${ }^{5}$ El Colegio Nacional, Ciudad de México, Mexico
}

Keywords: plant demography, fragmentation, defaunation, conservation, tropical reserves, cascading effects

\section{OPEN ACCESS}

Edited by:

Carlos Roberto Fonseca, Federal University of Rio Grande do

Norte, Brazil

Reviewed by:

Alexandre F. Souza,

Universidade Federal do Rio Grande

do Norte, Brazil

*Correspondence:

Miguel Martínez-Ramos mmartinez@cieco.unam.mx

Specialty section:

This article was submitted to

Conservation

a section of the journal

Frontiers in Ecology and Evolution

Received: 27 June 2016 Accepted: 22 August 2016

Published: 31 August 2016

Citation:

Martínez-Ramos $M$

Ortiz-Rodríguez IA, Piñero D, Dirzo $R$ and Sarukhán J (2016) Response:

Commentary: Anthropogenic

disturbances jeopardize biodiversity conservation within tropical rainforest

reserves. Front. Ecol. Evol. 4:108

doi: 10.3389/fevo.2016.00108

\section{A commentary on}

Commentary: Anthropogenic disturbances jeopardize biodiversity conservation within tropical rainforest reserves

by Arroyo-Rodríguez, V., and Melo, F. P. L. (2016). Front. Ecol. Evol. 4:73. doi: 10.3389/fevo. 2016.00073

In their commentary on our recent paper (Martínez-Ramos et al., 2016), Arroyo-Rodríguez and Melo (2016, hereafter referred to as A-R\&M) present imprecisions that need clarification to avoid misleading the readership of FEE regarding the contribution of our paper.

First, we focused on analyzing the effects of anthropogenic disturbances affecting a mediumsized (640 ha) tropical rainforest reserve (the Los Tuxtlas Research Station, protected by the National Autonomous University of Mexico, LTS). Our study was not designed to document landscape-level variation in the abundance of the palm Astrocaryum mexicanum among fragments in the Los Tuxtlas region (250,000 ha). Within LTS, we established a network of permanent plots to study this palm's demography, starting in 1975 when human impact, within and outside the reserve, was lower than in the subsequent years. Along 40 years, we observed a dramatic population outburst of the palm (Figure 1), with cascading consequences on biodiversity (reduction in abundance and diversity, and composition shifts of understory tree assemblages) and ecosystem functioning (changes in biomass and litter-fall processes). Using empirical, experimental, and modeling approaches, we show that such extraordinary palm population growth responded to anthropogenic activities (deforestation and defaunation) occurring in the surroundings of the LTS (Martínez-Ramos et al., 2016). This favored palm fecundity, seedling recruitment, and the survival and growth of juvenile and immature palms within a protected area immersed in a landscape of anthropogenic impact.

Second, we challenge A-R\&M's comment regarding the robustness of our study. We employed eight plots (0.06 ha each), taking advantage of the high local abundance of A. mexicanum in LTS. Indeed, in 1975 we tagged (and then followed) more than 2300 individuals including seedlings, juveniles, and adults. Our plots were large enough to derive robust estimates of size-specific demographic rates (survival, growth, and reproduction) and of the population growth rate per plot 


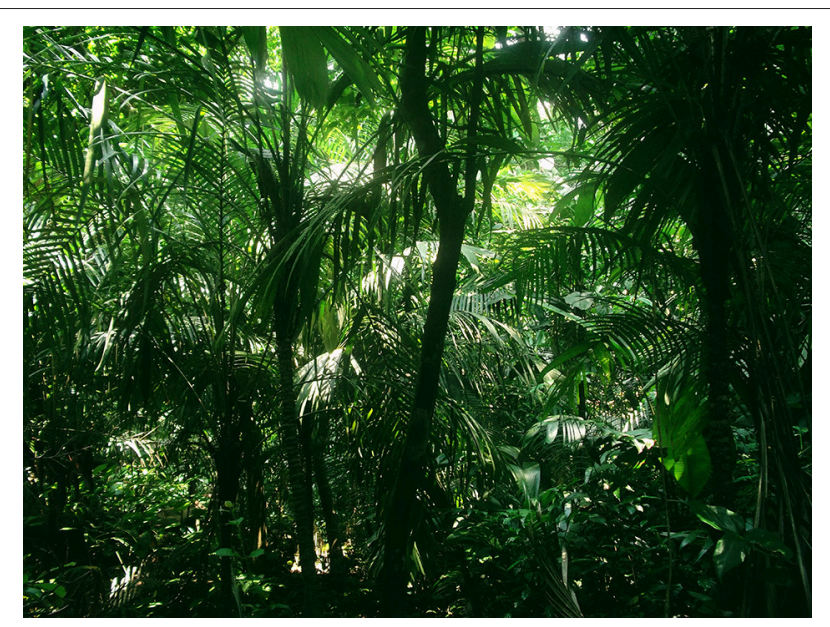

FIGURE 1 | In the Anthropocene, human impacts on tropical forests are threatening biodiversity, even inside reserves. In the Los Tuxtlas Station, SE Mexico, fragmentation and defaunation have conduced to the exponential growth of an understory palm with negative consequences for biodiversity conservation and ecosystem functioning. Image courtesy of Iván A. Ortiz-Rodríguez.

using matrix modeling. The plots were scattered in an area of 35 ha (not 10 ha, as mentioned by A-R\&M), encompassing the natural variation in population densities of the palm (Piñero et al., 1984), variations in topography, structure and composition of the forest (Piñero et al., 1977), and forest regeneration stages (Martínez-Ramos et al., 1988). In sum, we base our study on copious and long-term data.

Third, the palm population densities within LTS reported by A-R\&M are misleading as they counted palms with stems $\geq 1.3 \mathrm{~m}$ height. This is a critical drawback because we uncovered that the exponential growth of $A$. mexicanum is largely due to the extraordinary increase of palms $<1.3 \mathrm{~m}$ high. These smaller palms, younger than 35-50 years (Piñero et al., 1984), are the ones mostly favored by the environmental changes (increased light availability due to edge effects) occurring inside the reserve over the past 40 years. On the other hand, the mean palm densities reported by A-R\&M for the years 2003 (900/ha) and 2015 (1180/ha) correspond closely with ours, considering palms $\geq 1.3 \mathrm{~m}$ height (Martínez-Ramos et al., 2016) for the years 2005 (952) and 2013 (1129). Furthermore, with their data, it can be calculated that in 12 years (2003-2015) the palm population grew $31 \%\left[(1180-900)^{*} 100 /(900)\right]$, corresponding to a finite population growth rate $\left[\lambda=(1180 / 900)^{(1 / 12)}\right]$ of 1.023 ind ind $^{-1}$ $\mathrm{yr}^{-1}\left(2.3 \% \mathrm{yr}^{-1}\right)$. This rate is similar to that we report $(2.9 \%$ per year) and would lead to a practically equal estimate of the population growth using our population density of palms $\geq$ $1.3 \mathrm{~m}$ height: $\lambda=1.022$ for the $2005-2013$ period. Considering that population density values of A-R\&M were obtained in areas different from ours within LTS, these results support that the population outburst of $A$. mexicanum we report is becoming widespread throughout this small reserve.

Fourth, it is unfitting to compare our palm population densities within LTS with those in forest fragments outside the reserve, as done by AR\&M. Theirs are unprotected fragments exposed to multiple anthropogenic impacts (human and livestock trampling, cattle grazing, fires, logging, fruit harvesting) that directly affect the population dynamics of A. mexicanum. For example, the palm's inflorescences are avidly consumed by local people, and are extensively harvested for sale in markets (Quero, 1992; Centurión-Hidalgo et al., 2009). Furthermore, people harvest the stems of large adult palms for use as agricultural tools, killing the single-stemmed palms. These activities have strong negative demographic consequences, reducing fruit production, seedling recruitment, and increasing adult mortality, thus reducing overall palm population density. By contrast, within the LTS these extractive activities are not allowed. It is therefore not surprising that in unprotected fragments, as those used by AR\&M, palm population densities are varied, and often very low.

Fifth, it is also not surprising to find a positive relationship between tree species diversity and density of palms in the unprotected fragments studied by A-R\&M. This relationship readily arises if tree species diversity varies across fragments while palm population density decrease with the intensity of anthropogenic disturbance in the fragments. The A. mexicanum populations of A-R\&M were studied using single-time, static counts, making it impossible to know to what extent palm population density and tree assemblages have changed over time in their fragments. In contrast, we used a baseline population from 1975, followed for 4 decades, from which palm demography and the causes and consequences of the population explosion were assessed while we quantified the structure, composition and attributes of the ecosystem through time.

These arguments make it clear that A-R\&M confused the essence of our article and, unfortunately, in so doing, provided a misleading view of the population dynamics of $A$. mexicanum both inside and outside the LTS reserve. Nevertheless, we concur with them that more efforts should be made to reach a comprehensive picture of the nuanced, frequently cryptic effects of anthropogenic activities on biodiversity. In this sense, studies like ours in PNAS and those mentioned by A-R\&M are complementary and necessary to fully assess the condition of biodiversity in human modified landscapes. Finally, in accordance with Laurance et al. (2012) we emphasize the urgent need to monitor the health of ecosystems protected within reserves in the face of anthropogenic impacts occurring in their periphery.

\section{AUTHOR CONTRIBUTIONS}

$\mathrm{MM}$, wrote the first version of the paper; IO, DP, RD, and JS reviewed and gave feedback on the writing of the paper.

\section{ACKNOWLEDGMENTS}

This study was supported by grants from the Mexican National Council for Science and Technology (CONACyT-Mexico). We thank Los Tuxtlas Tropical Field Station, Institute of Biology, UNAM, for fieldwork facilities provided. 


\section{REFERENCES}

Arroyo-Rodríguez, V., and Melo, F. (2016). Commentary: anthropogenic disturbances jeopardize biodiversity conservation within tropical rainforest reserves. Front. Ecol. Evol. 4:73. doi: 10.3389/fevo.2016. 00073

Centurión-Hidalgo, D., Alor-Chávez, M. J., Espinosa-Moreno, J., Gómez-García, E., Solano, M. L., and Poot-Matu, J. E. (2009). Nutritional Content of Palm Inflorescences in the Tabasco Mountains, Vol. 25. Villahermosa: Universidad y Ciencia, 193-199.

Laurance, W. F., Useche, D. C., Rendeiro, J., Kalka, M., Bradshaw, C. J. A., Sloan, S. P., et al. (2012). Averting biodiversity collapse in tropical forest protected areas. Nature 489, 290-294. doi: 10.1038/nature 11318

Martínez-Ramos, M., Ortíz-Rodríguez, I. A., Piñero, D., Dirzo, R., and Sarukhán, J. (2016). Anthropogenic disturbances jeopardize biodiversity conservation within tropical rainforest reserves. Proc. Natl. Acad. Sci. U.S.A. 113, 5323-5328. doi: $10.1073 /$ pnas. 1602893113

Martínez-Ramos, M., Sarukhán, J., and Piñero, D. (1988). "The demography of tropical trees in the context of forest gap dynamics: the case of Astrocaryum mexicanum at Los Tuxtlas tropical rain forest," in Plant population ecology $b$, eds D. Davy, M. Hutchings, and A. R. Watkinson (Oxford: Blackwell), 293-313.
Piñero, D., Martínez-Ramos, M., and Sarukhán, J. (1984). A population model of Astrocaryum mexicanum and a sensitivity analysis of its finite rate of increase. J. Ecol. 72, 977-991.

Piñero, D., Sarukhán, J., and González, E. (1977). Estudios demográficos en plantas. Astrocaryum mexicanum Liebm. 1. Estructura de poblaciones. Bol. Soc. Bot. Mex. 37, 69-118.

Quero, H. (1992). Current status of Mexican palms. Principes 36, 203-216.

Conflict of Interest Statement: The authors declare that the research was conducted in the absence of any commercial or financial relationships that could be construed as a potential conflict of interest.

The reviewer AS and handling Editor declared their shared affiliation, and the handling Editor states that the process nevertheless met the standards of a fair and objective review.

Copyright (c) 2016 Martínez-Ramos, Ortiz-Rodríguez, Piñero, Dirzo and Sarukhán. This is an open-access article distributed under the terms of the Creative Commons Attribution License (CC BY). The use, distribution or reproduction in other forums is permitted, provided the original author(s) or licensor are credited and that the original publication in this journal is cited, in accordance with accepted academic practice. No use, distribution or reproduction is permitted which does not comply with these terms. 